\title{
Towards biotechnological processing of calcium phosphates
}

\section{Karlis Agris Gross}

\author{
Biomaterials research laboratory, Riga Technical University, Latvia \\ Department of Materials Engineering, Monash University, Australia \\ kgross@rtu.lv
}

Keywords: biomineralization, meta-stable phases, transient mineral phase, calcification, bone

\begin{abstract}
Transient or metastable phases offer an intermediate phase with additional flexibility for creating the end product. The processing pathway remains unknown when the final product is viewed. Biological processes frequently employ the amorphous phase as the transition phase. This is shown in mineralized tissues: invertebrates, pathological calcified deposits and murine fetal teeth. After a fast transition from an amorphous calcium phosphate to crystalline material, smaller changes occur over time. For an appreciation of the transition state, crystallinity is defined and measurement methods outlined. Biotechnology using transition material states offers fast, low temperature access to nanosized high temperature phases. Alfa tricalcium phosphate and apatite is made by a phase transition, but peroxyapatite requires long-range diffusion within the same structure. Tetracalcium phosphate is also possible, but this requires multiple transition states and phase decomposition. The pathway via the amorphous state offers an alternative route to biologically important materials.
\end{abstract}

\section{Introduction}

Biological processing utilizes small transitions in energy states towards the final material state. These transitions create new processing pathways for faster production and improved material properties. With focus on the final product, industrial processes have directed effort to producing the most stable material, however there is great potential and opportunity by passing through less stable states to create the end product. Processes in nature conserve energy by using phase transitions from less stable states. It will be shown not only that traditional materials can be formed, but a new range of materials become available options and thereby diversify access to a complete range of materials.

A transition in energy states is not available for all materials; only a selected few material systems. Biological materials change the structure more frequently than synthetic materials. Proteins are recognized for their ability to restructure thereby activating processes in contact with the surroundings. Biominerals have fewer degrees of freedom, and undergo three changes in state from a disorganized structure to a structured arrangement. The case for a material with a chemistry of hydroxyapatite $\left(\mathrm{Ca}_{10}\left(\mathrm{PO}_{4}\right)_{6}(\mathrm{OH})_{2}\right)$ is shown in Fig 1. Calcium phosphates provide an example of a material with different energy states where amorphous calcium phosphate (ACP) is widely found in nature, a material state commonly traversed before the formation of crystallized forms.

Gibbs free energy

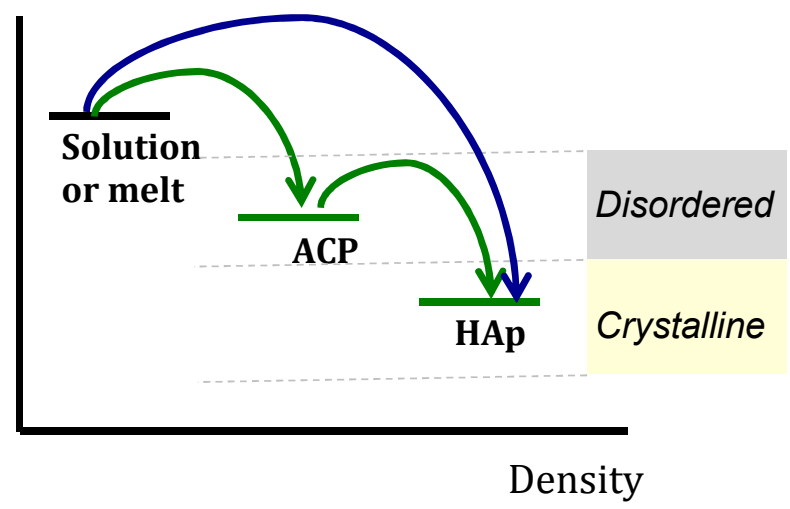

Figure 1. The three energy states of calcium phosphate representing mobile ionic species found in solutions or a melt, an amorphous phase representing the disordered state, and a crystalline material (hydroxyapatite abbreviated as HAp) depicting the lowest free energy.

Undesired calcification in the body and biomineralization (in invertebrates and 
vertebrates) often consist of ACP. This supports the notion that the first phase may be amorphous. In the body, amorphous calcified deposits have been found in kidney stones $[1,2]$ and in the blood vessels [3]. In bone, only the less stable octacalcium phosphate has been identified as a precursor to hydroxyapatite [4], but Posner's suspicion of the amorphous phase as the first mineral state of bone [5] has still not been shown. The outer layer forming murine enamel shows signs of an amorphous transient phase [6]. In invertebrates and vertebrates, ACP has been widely found by Lowenstam [7].

Of all the calcium phosphates, apatite is the most stable and may explain the inclusion of apatite in biomineralization, Fig 2. An amorphous phase consisting of a chemistry that allows crystallization of apatite occurs in mollusca, chordates and arthropods. The amorphous phase is more common in invertebrates than in vertebrates [8]. The second most common is whitlockite $(\mathrm{Mg}$ enriched tricalcium phosphate), found in mollusca and annelida. Brushite is the least common only found in mollusca.

\begin{tabular}{|c|c|c|c|c|}
\hline Mollusca & Brushite & Whitlockite & Apatite & \\
\hline Annelida & $x$ & & $x$ & \\
\hline Chordata & $x$ & $x$ & & $\begin{array}{l}\text { Figure 2. Amorphous forms of calcium } \\
\text { phosphates (names after the crystalline } \\
\text { analogue) in organisms showing wider }\end{array}$ \\
\hline Arthropoda & $x$ & $x$ & & apatites (from [7]). \\
\hline
\end{tabular}

\section{Formation of amorphous calcium phosphate}

The amorphous phase holds capabilities that offer advantages in the architecture and function of materials. Since an amorphous phase has no internal structure, then the shape of an amorphous phase can be rounded. The amorphous phase can be viewed as the design stage of materials made more permanent by crystallization; quickly assembled compared to crystalline materials and rapidly disassembled by dissolution. This has advantages in the transportation of calcium and phosphate to the building site of bone. ACP is transported with casein in milk to newborn for bone generation.

The amorphous phase in nature is formed in aqueous environments, but synthetic processing routes may also form ACP in dry conditions. The reader is directed to review articles for more details on ACP precipitation in aqueous conditions $[9,10]$. In dry conditions, the amorphous phase may be created at the atomic level, rapid solidification of melts or introducing defects into the crystalline material. Most research activity on precipitation is in geochemistry, structural biology and dentistry, followed by rapid solidification due to its appearance in hydroxyapatite coated implants [11], Fig 3. Recent interest on sputtered films comes from a better capability to control surface topography.

Solidification to an amorphous phase is achieved by quenching a melt or by collecting condensing charged species on a surface. Sputtering - uses a plasma to generate ions in the gas phase that are then collected on a surface [12].

The amorphous phase may also be formed in solids by reducing the long-range order. Energy intensive processes introduce defects into crystalline solids. Ball-milling uses mechanical methods to introduce defects [13]. The second process involves irradiation [14]. Both are energy intensive and either expensive or time consuming. 


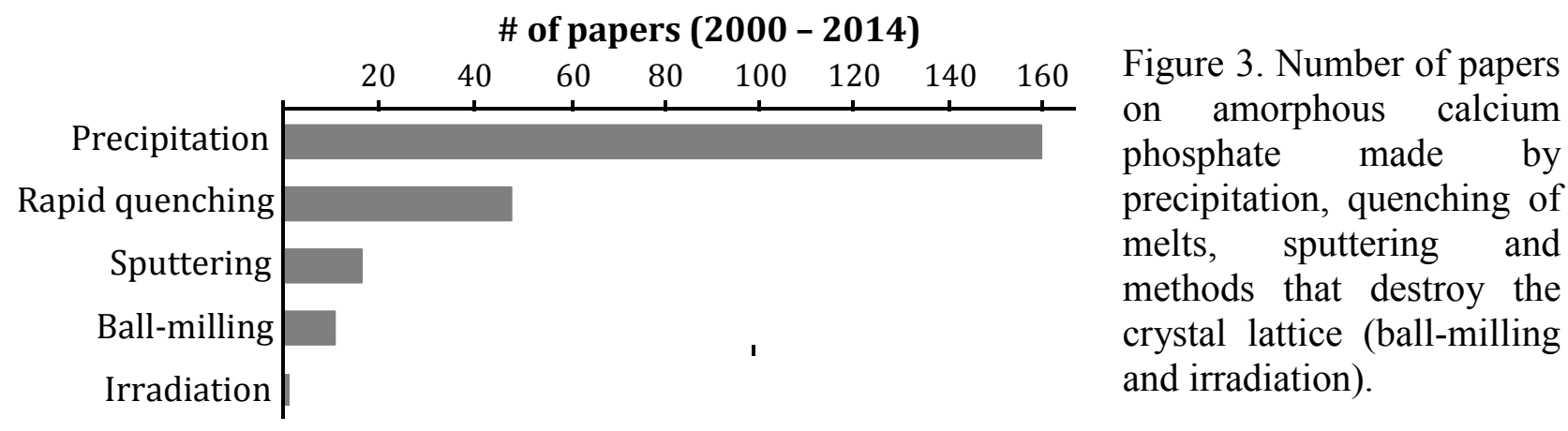

Departure from the amorphous state will introduce some order and this is referred to as crystallinity. Crystallinity will be defined and the measurement methods discussed before showing several methods to transform the amorphous state into a crystalline phase.

\section{Definition of crystallinity}

There are three definitions of crystallinity, relating to three microstructures; 1) an amorphous phase mixed with a crystalline material, 2) nanosized particles and 3) a crystalline phase with defects.

1. Amount of crystalline phase in the amorphous phase. By overcoming the activation energy, crystalline nuclei will form and grow in size. As the volume of the crystalline phase increases in an amorphous matrix, so does the crystallinity.

2. Particle/crystal or grain size. Material may be a crystalline powder or solid. Smaller particles possess a larger surface area where disorder will be more predominant, and so the volume of material in a disordered arrangement is greater. Similarly, smaller grains in a solid increase the volume of disordered material in the grain boundary and so decreases the crystallinity.

3. Degree of order in the crystalline phase. The degree of order may be lowered in a crystalline material by introducing defects. Hydroxyapatite is well recognized for a calcium and hydroxyl deficiency, and phosphate replacement with carbonate; all introduce defects, but carbonate additionally imparts stress $[15,16]$. High-energy processes also introduce defects.

\section{Measurement of crystallinity}

The amorphous phase has received less attention since it is more difficult to characterize. Small unidentifiable materials have been described as amorphous [17], but this may not be true. Crystallinity can be measured in one of four ways. The most common method for measuring crystallinity registers a departure from a crystalline state. As a complimentary technique, changes in bonding are usually investigated. Less attention is directed to a change in enthalpy and microscopy to observe directly observed amorphous and crystalline regions. These will be explained in turn.

1. Structure. X-ray diffraction provides the first glimpse of whether it is amorphous or crystalline. An amorphous phase appears as a single low intensity, broad peak centred at about $30^{\circ}$. If a crystalline phase is present, then narrow peaks will superimpose the amorphous halo. There is a dispute whether the broad peak arises from an amorphous phase or nanosized crystals, and so it is usually termed "X-ray amorphous", requiring further investigation. The second sign of low crystallinity is lower intensity or broad X-ray diffraction peaks. A part of the peak breadth is due to the defects in the apatite structure. For comparison, an X-ray diffraction pattern of an amorphous, nanocrystalline and larger particle size powder is shown in Figure 4. Hydroxyapatite is calcium deficient and nanosized; both the point defects and the nano size contribute to a broad crystalline peak. 


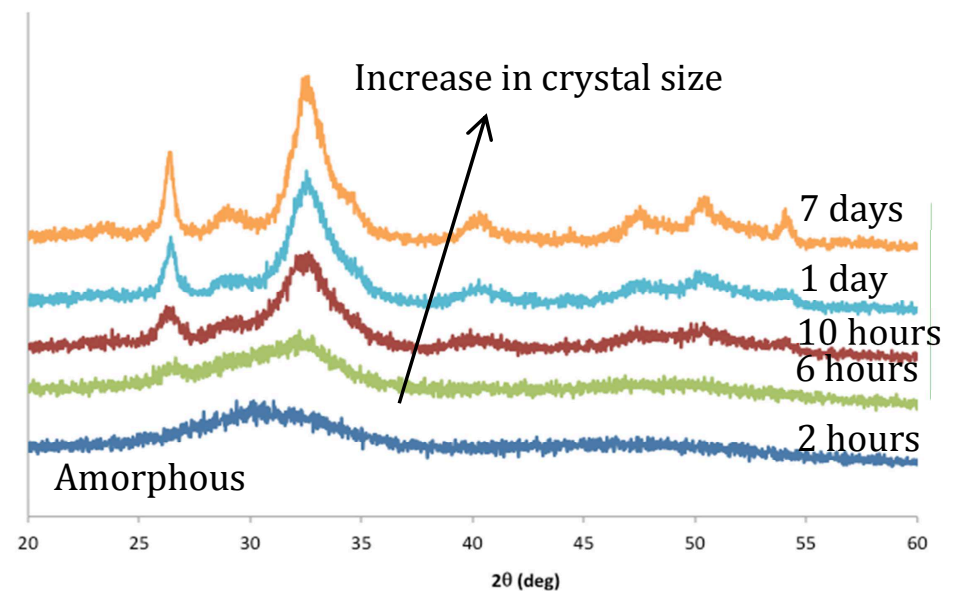

Figure 4. X-ray diffraction showing the transition in water at room temperature from an amorphous phase at 2 hours to a nanosized calcium deficient hydroxyapatite at 6 hours followed by crystal growth (from [18]).

Electron diffraction is a more reliable indicator of the amorphous phase showing diffuse diffraction rings or spots. The challenge with electron diffraction is to prevent crystallization of ACP from exposure to the electron beam.

2. Bonding. Fourier transform infra-red spectroscopy is the most often used spectroscopic method. Phosphate absorption peaks are wide, as opposed to sharp phosphate peaks found in X-ray diffraction. Measurement of crystal size and/or order in the lattice has been measured by a ratio of phosphate band intensities (at different wavelengths) to give a crystallinity index, $\left(\mathrm{I}_{565}+\mathrm{I}_{605}\right) / \mathrm{I}_{595}$ [19]. Raman spectroscopy only presents a broad peak at $950 \mathrm{~cm}^{-1}$ from an amorphous phase arising from the $1.5 \AA \mathrm{P}-\mathrm{O}$ bond length [20], in support of the diffuse XRD peak centred at $30^{\circ}$. Extended $\mathrm{X}$-ray absorption fine structure is a complimentary technique that assesses the nearest neighbor to a selected atom, such as calcium, but is not that accessible. Spectra deconvolution helps to identify the peaks [21].

3. Thermal analysis. Heating the amorphous phase will supply energy to overcome the activation energy barrier and crystallize ACP, allowing the material to take up a lower Gibbs free energy [22]. A sharper exothermic peak will represent a material that readily crystallizes. For higher sensitivity, powder is placed in a platinum crucible and heated at a faster rate.

4. Microscopy. The amorphous phase has a different refractive index [23] and cathodoluminescence [24]. This allows viewing the distribution of crystalline areas in an amorphous phase. Work is still to be performed to determine the effect of defects on optical properties.

The amorphous state requires careful identification since these materials may also possess a residual stress - indirectly inferred from a property measurement such as nanoindentation. Amorphous materials may be quasi-amorphous or be in a different structural arrangement.

\section{The sequence of phase transitions in nature}

The amorphous phase is most commonly the initial material state - a transient phase before conversion to a more stable phase. In chiton teeth, transformation starts at one end of the row of teeth showing impending transformation in the next teeth until the entire row has crystallized [25]. In bone, the original mineral has been proposed to be octacalcium phosphate (a hydrated calcium phosphate) that upon dehydration is also enriched in calcium to form the denser apatite structure. With age, the crystallinity in bone (crystal size) increases [26, 27]. In newborn and infants, the lower crystallinity apatite and more flexible bones increase the resistance to fracture.

The amorphous phase increases resistance to fracture, solubility and the rate of bone formation. Indentation on water-free amorphous calcium phosphate (produced by plasma spraying) has a 5 
times greater load for crack initiation compared to single crystal hydroxyapatite [28]. The solubility of an amorphous phase is about 50 to 100 times greater than sintered hydroxyapatite [29]. Higher solubility is accompanied by a faster bone growth around implants.

In the body, collagen plays a strategic role in placing the nano-sized mineral in a hierarchical structure, and supports the inclusion of an apatite with low structural order [30]. The functional motifs on the extracellular proteins then direct crystallization [31]. Where calcification occurs without the assistance of proteins, such as in kidney stones, the full transition from an amorphous phase to an apatite has been observed [32]. Spherical nano-deposits in patients with coronary disease are of lower crystallinity than in bone; both the shape and the lower crystallinity suggest ACP as the initial state, but these deposits have not been analyzed over the entire time span [33].

\section{Amorphous calcium phosphate - the transient state before crystallization}

The biotechnological approach involves the transition from an amorphous phase to the crystalline phase. Four examples to be given represent three types of transitions. The first case involves direct crystallization. The example of tricalcium phosphate and apatite will be shown. The second phase change involves crystallization accompanied by diffusion of a new species. The third phase change involves initial crystallization, followed by decomposition to release an undesired chemical species, followed by a solid-state reaction between nanoparticles to produce tetracalcium phosphate.

The processability via the amorphous state requires a stable amorphous phase. Early studies showed how hydrolysis of phosphate crystallized a calcium deficient apatite [34]. Recent studies have confirmed the earlier observation by tracking changes in the X-ray diffraction pattern, Fig 3. Crystallization can be delayed by the incorporation of cations ( $\mathrm{Mg}, \mathrm{Zn}$ ) [35], anions (pyrophosphate [36] and carbonate [37]) and inclusion of organic molecules (biomacromolecules such as casein [38], polysaccharides such as cyclodextrins [39] and alendronate [40]). The amorphous phase can be stabilized by freeze drying [21] and storage at low temperature.

Instead of lowering the activation energy for heterogeneous nucleation, other forms of energy may contribute to overcoming the activation energy barrier. Elevated temperatures provide the easiest option - initially investigated by Eanes [41]. Smaller particles crystallize at a lower temperature and see a lower activation energy barrier. Residual stress (introduced by thermal spraying [28]) and chemical modifications can further lower the activation energy. Transition to the crystal phase from an amorphous phase introduces material phases not possible with traditional synthesis routes.

According to the Ostwald rule, the next most similar phase to ACP will crystallize, explaining why the $\alpha$ phase forms from the amorphous phase instead of the $\beta$ phase. The $\alpha^{\prime}$-TCP phase is expected, but this is highly unstable at lower temperature, giving priority to the next high temperature allotrope, $\alpha$-TCP [42]. $\beta$-TCP is not made directly from the amorphous phase. It is conventionally made by decomposition of calcium deficient HAp [43], Fig 5. Starting from the amorphous phase requires a lower activation energy and thereby retains the initial particle characteristics with preferential formation of the alpha phase.

The second phase transformation, illustrates easier incorporation of cations to form apatite. Precipitation of zinc-substituted hydroxyapatite commonly results in calcium deficient apatite that upon heating will decompose to tricalcium phosphate and apatite. A zinc-substituted hydroxyapatite from ACP however is thermally stable allowing further heating. In addition to cation-modified apatites, anion modified apatites such as peroxyapatites are also possible. 


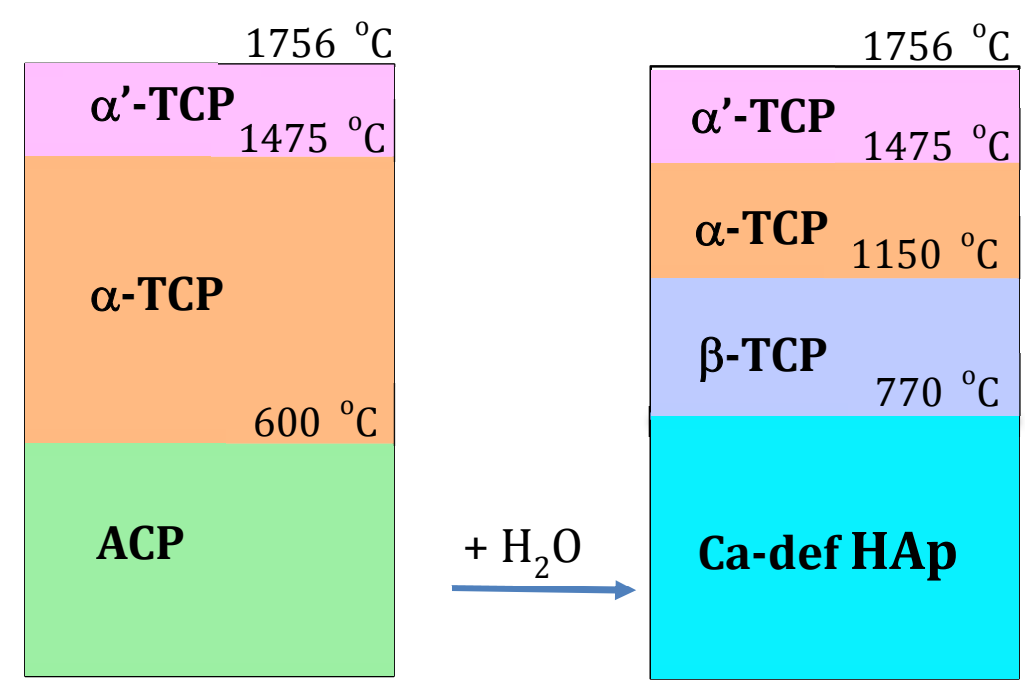

Figure 5. Phase transformation in the tricalcium phosphate system starting from an amorphous phase or a calcium deficient apatite.

The transition phase may require long-range diffusion of a gas. A lower density amorphous structure provides greater mobility of gaseous species to form peroxyapatite. Normally hydroxyapatite is heated to $1350{ }^{\circ} \mathrm{C}$, but a phase transition from an amorphous phase in oxygen has shown that only $130{ }^{\circ} \mathrm{C}$ is required. [44, 45]. This approach is fast, requires less energy than high temperature processing with the potential for high peroxy ion inclusion.

The most complex of phase transformations includes a phase transition followed by a transformation requiring long-range diffusion. This is the case for tetracalcium phosphate where an amorphous phase crystallizes to apatite, then carbonate is released to create oxyapatite and calcium oxide, both meta-stable phases that react to form tetracalcium phosphate [46]. This chain of transformations includes three consecutive stages of transient meta-stable phases (an amorphous phase, carbonated apatite, oxyapatite).

\section{Summary}

The amorphous phase represents the most common transient phase and represents an intermediate state with a lower activation energy barrier en route to the crystal state. In nature, the amorphous phase is frequently used in aqueous environments, but this work has shown the use of heat to overcome the activation energy barrier and create a range of crystalline calcium phosphatestricalcium phosphate, apatite, peroxyapatite and tetracalcium phosphate. These transitions are fast and occur by short-range diffusion, or require a change in chemistry and progress by long-range diffusion.

\section{Acknowledgements}

The EU funded project "Refined Step", nr. PIRSES-GA-2013-612691 described in www.createyourbiomaterial.eu is acknowledged for the development of ideas described here.

\section{References}

[1] Zelenkova M, Sohnel O, Grases F. Ultrafine structure of the hydroxyapatite amorphous phase in noninfectious phosphate renal calculi. Urology 2012;79:968.e1-.e6.

[2] Gower LB, Amos FF, Khan SR. Mineralogical signatures of stone formation mechanisms. Urol Res 2010;38:281-92.

[3] Hsu HHT, Camacho NP, Sun F, Tawfik S, Aono H. Isolation of calcifiable vesicles from aortas of rabbits fed with high cholesterol diets. Atherosclerosis 2000;153:337-48. 
[4] Grynpas MD. Transient precursor strategy or very small biological apatite crystals? Bone 2007;41:162-64.

[5] Boskey AL. Amorphous calcium phosphate: The contention of bone. J Dental Res 1997;76:1433-36.

[6] Liu Y, Kim YK, Dai L, Li N, Khan SO, Pashley DH, et al. Hierarchical and non-hierarchical mineralisation of collagen. Biomaterials 2011;32:1291-300.

[7] Lowenstam HA. Minerals formed by organisms. Science 1981;211:1126-31.

[8] Lowenstam HA. Phosphatic hard tissues of marine invertebrates: their nature and mechanical function, and some fossil implications. Chem Geol 1972;9:153-66.

[9] Dorozhkin SV. Amorphous calcium orthophosphates: Nature, chemistry and miomedical applications. Int J Mater Chem 2012;2:19-46.

[10] Combes C, Rey C. Amorphous calcium phosphates: Synthesis, uses and properties in biomaterials. Acta Biomater 2010;6:3362-78.

[11] Gross KA, Berndt CC, Herman H. Amorphous phase formation in plasma-sprayed hydroxyapatite coatings. J Biomed Mater Res 1998;39:407-14.

[12] Lopez EO, Mello A, Sendao H, Costa LT, Rossi AL, Ospina RO, et al. Growth of crystalline hydroxyapatite thin films at room temperature by tuning the energy of the RF-sputtering plasma. ACS Appl Mater Interfaces 2013;5:9435-45.

[13] Gbureck U, Barralet JE, Radu L, Klinger HG, Thull R. Amorphous alpha-tricalcium phosphate: Preparation and aqueous setting reaction. J Am Ceram Soc 2004;87:1126-32.

[14] Miro S, Constantin JM, Bardeau JF, al. e. Raman spectroscopy study of damage induced in fluorapatite by swift heavy ion irradiation. . J Raman Spectrosc 2011;42:2036-41.

[15] McElderry JDP, Zhu P, Mroue KH, Xu J, Pavan B, Fang M, et al. Crystallinity and compositional changes in carbonated apatites: Evidence from 31P solid-state, Raman and AFM analysis. J Solid State Chem 2013;206:192-98.

[16] Yerramshetty JS, Akkus O. The associations between mineral crystallinity and the mechanical properties of human cortical bone. Bone 2008;42:476-82.

[17] Berg WA, Arnoldus CL, Teferra E, Bhargavan M. Biopsy of amorphous breast calcifications: Pathologic outcome and yield at stereotactic biopsy. Radiology 2001;221:495-503.

[18] Gross KA, Andersons J, Misevicius M, Svirksts J. Traversing phase fields towards nanosized beta tricalcium phosphate. Key Engin Mater 2014;587:97-100.

[19] Greene EF, Tauch S, Webb E, Amarasiriwardena D. Application of difuce reflectance infrared Fourier transform spectroscopy (DRIFTS) for the identification of potential diagenesis and crystallinity changes in teeth. Microchemical Journal 2004;76:141-49.

[20] Popovic L, de Waal D, Boeyens JCA. Correlation between Raman wavenumbers and P-O bond lengths in crystalline inorganic phosphates. J Raman Spectrosc 2005;36:2-11.

[21] Brangule A, Gross KA. Effect of drying conditions on amorphous calcium phosphate. Key Engin Mater 2015.

[22] Gross KA, Komarovska L, Viksna A. Efficient zinc incorporation in hydroxyapatite through crystallization of an amorphous phase could extend the properties of zinc apatites. J Austral Ceram Soc 2013;49:129-35.

[23] Gross KA, Berndt CC, Herman H. Amorphous phase formation in plasma-sprayed hydroxyapaite coatings. J Biomed Mater Res 1998;39:407-14.

[24] Gross KA, Phillips MR. Identification and mapping of the amorphous phase in plasma-sprayed hydroxyapatite coatings using cathodoluminescnece microscopy. J Mater Sci: Mater Med 1998;9:797-802.

[25] Weaver JC, Wang Q, Miserez A, Tantuccio A, Stromberg R, Bozhilov KN, et al. Analysis of an ultra hard magnetic biomineral in chiton radular teeth. Materials Today 2010;13:42-52.

[26] Chatterji S, Wall JC, Fehhrey JW. Age-related changes in the orientation and particle size of the mineral phase in human femoral cortical bone. Calcifed Tissue International 1981;33:567-74.

[27] Paschalis EP, Betts F, DiCarlo E, Mendelsohn R, Boskey AL. FTIR microspectroscopic analysis of normal human cortical and trabecular bone. Calcif Tissue Int 1997;61:480-86. 
[28] Saber Samandari S, Gross KA. Amorphous calcium phosphate offers improved crack resistance: A design feature from nature? Acta Biomater 2011;7:4235-41.

[29] Le Geros RZ. Biodegradation and bioresorption of calcium phosphate ceramics. Clin Materials 1993;14:65-88.

[30] Tsuji T, Onuma K, Yamamoto A, Lijima M, Shiba K. Direct transformation from amorphous to crystalline calcium phosphate facilitated by motif-programmed artificial proteins. PNAS 2008;105:16866-70.

[31] Liu Y, Kim YYK, Dai L, Li N, Khan SO, Pashley DH, et al. Hierarchical and non-hierarchical mineralisation of collagen. Biomaterials 2011;2011:1291-300.

[32] Tiselius HG. The role of calcium phosphate in the development of Randall's plaques. Orolithiases 2013;41:369-77.

[33] Bertazzo S, Gentleman E, Cloyd KL, Chester AH, Yacoub MH, Stevens MM. Nano-analytical electron microscopy reveals fundamental insights into human cardiovascular tissue calcification. Nature Materials 2013;12:576-83.

[34] Heughebaert JC, Montel G. Revue de Physique Appliquee 1977;12:691-94.

[35] Root MJ. Inhibition of the amorphous calcium phosphate phase transformation reaction by polyphosphates and metal ions. Calcif Tissue Int 1990;47:112-16.

[36] Ajibola VO, Thomas SA. Transformation of amorphous calcium phosphate hydroxyapatite in the presence of some ions. Bull Chem Soc Ethiop 1997;11:19-24.

[37] LeGeros RZ. Formation and transformation of calcium phosphates: relevance to vascular calcification. Z Kardiol 2001;90:116-24.

[38] McCann TCA, Kearney RD, Buchheim W, Posner AS, Blumenthal NC. Amorphous calcium phosphate in casein micelles of bovine milk. Calcif Tissue Int 1983;35:821-23.

[39] Li Y, Wiliana T, Tam KC. Synthesis of amorphous calcium phosphate using various types of cyclodextrins. Mater Res Bull 2007;42:820-27.

[40] Kim CW, Yun YP, Lee HJ, Hwang YS, Kwon IK, Lee SC. In situ fabrication of alendronateloaded calcium phosphate microspheres: controlled release for inhibitin of osteoclastogenesis. J Control Release 2010;147:45-53.

[41] Eanes ED. Thermochemical studies on amorphous calcium phosphate. Calc Tiss Res 1970;5:133-45.

[42] Vecbiskena L, Gross KA, Riekstina U, Thomas YCK. Formation of calcium-deficient hydroxyapatite via hydrolysis of nano-sized pure alpha-tricalcium phosphate. InterAcademia 2015.

[43] Raynaud S, Champion E, Bernache-Assollant D. Calcium phosphate apatites with variable $\mathrm{Ca} / \mathrm{P}$ atmoic ratio II. Calcination and sintering. Biomaterials 2002;23:1073-80.

[44] Gross KA, Jersova A, Viksna A. Synthesis of peroxyapatite by hydrothermal processing. Key Engin Mater 2015;631:88-92.

[45] Osite A, Gross KA, Viksna A, Poplausks R. Hydrothermally synthesized strontium peroxyapatite. InterAcademia 2015.

[46] Gross KA, Rozite E. Synthesis of tetracalcium phosphate at reduced temperatures. Key Engin Mater 2015;631:93-8. 